\title{
Management of Symptomatic Meckel's Diverticulum in Infants and Children
}

\author{
Rajendra K. Ghritlaharey ${ }^{10}$ \\ 1 Department of Paediatric Surgery, Gandhi Medical College and \\ Associated Kamla Nehru and Hamidia Hospitals, Bhopal, Madhya \\ Pradesh, India \\ Ann Natl Acad Med Sci (India) 2022;58:11-16.

\begin{abstract}
Address for correspondence Rajendra K. Ghritlaharey, MS, MCh, FAIS, MAMS, DLitt, Department of Paediatric Surgery, Gandhi Medical College and Associated Kamla Nehru and Hamidia Hospitals, Bhopal 462001, Madhya Pradesh, India

(e-mail: drrajendrak1@rediffmail.com).
\end{abstract}

\begin{abstract}
Keywords

- children

- infants

- intestinal obstruction

- intussusception

- Meckel's diverticulum

- Meckel's diverticulectomy

- perforation peritonitis

Objectives The primary objective of the present study was to review the demographics of infants and children operated upon for Meckel's diverticulum. The secondary objectives were to review the clinical characteristics, surgical procedures performed, postoperative complications, and the outcome.

Materials and Methods This study is a single-institutional, retrospective study and descriptive in nature. It consisted of infants and children below 12 years who were operated upon for Meckel's diverticulum at the author's institute and included data from January 1, 2000 to December 31, 2020.

Results Eighty-four children below 12 years were operated upon for Meckel's diverticulum during the study period. The ratio for males to females was $3: 1$. This study consisted of infants, $(n=22,26.19 \%)$, children of 1 to 5 years of age ( $n=19$, $22.61 \%)$, and children of 6 to 12 years of age ( $n=43,51.19 \%)$. Clinically, children with Meckel's diverticulum presented in the following order of frequency: (1) intestinal obstruction ( $n=59,70.23 \%$ ), (2) perforation peritonitis ( $n=17,20.23 \%)$, (3) lower gastrointestinal bleeding ( $n=4,4.76 \%)$, and (4) incidental finding $(n=4,4.76 \%)$. In 35 (41.66\%) children, bowel gangrene was detected. One-fifth $(n=17)$ of Meckel's diverticulum was responsible for the secondary intussusception. The surgical procedures were performed in the following order of frequency: (1) resection of Meckel's diverticulum, an adjacent segment of ileum and ileoileal anastomosis ( $n=36,42.85 \%$ ); (2) Meckel's diverticulectomy ( $n=32,38.09 \%$ ); (3) resection of Meckel's diverticulum, an adjacent segment of ileum with or without cecum and an ileostomy ( $n=12$, 14.28\%); and (4) resection of Meckel's diverticulum, an adjacent segment of ileum, cecum, part of the colon, and ileocolic anastomosis $(n=4,4.76 \%)$. In 8 (9.52\%) children, complications were documented during the postoperative period. The present study observed three (3.57\%) deaths during the postoperative period.

Conclusion Meckel's diverticulum was one of the common causes of acute intestinal obstruction in infants and older children. Ninety percent of children with Meckel's diverticulum presented with features of an acute abdomen. Forty percent of children evidenced bowel gangrene during the surgical procedures. In these children, early
\end{abstract}

published online November 5, 2021
DOI https://doi.org/

$10.1055 / \mathrm{s}-0041-1739190$ ISSN 0379-038X.
(C) 2021. National Academy of Medical Sciences (India). All rights reserved.

This is an open access article published by Thieme under the terms of the Creative Commons Attribution-NonDerivative-NonCommercial-License, permitting copying and reproduction so long as the original work is given appropriate credit. Contents may not be used for commercial purposes, or adapted, remixed, transformed or built upon. (https://creativecommons.org/ licenses/by-nc-nd/4.0/)

Thieme Medical and Scientific Publishers Pvt. Ltd., A-12, 2nd Floor, Sector 2, Noida-201301 UP, India 
diagnosis, timely referral, and institution of surgical therapy for acute abdomen/intestinal obstruction may prevent the development of bowel gangrene and the requirement of bowel resections to some extent.

\section{Introduction}

Meckel's diverticulum is one of the commonest anomalies, among all the anomalies of the gastrointestinal tract. ${ }^{1,2}$ It is also the commonest among all the anomalies of the vitelline duct. ${ }^{3,4}$ The word Meckel's diverticulum was derived from "Johann Friedrich Meckel" the Younger (1781-1833). ${ }^{4}$ It is considered a disease of infants and children, but it also occurs in older children and adults. ${ }^{5-8}$ Most commonly, it is asymptomatic. Clinical presentation varies from study to study and varies with age. ${ }^{5-10}$ Meckel's diverticulum is also found as an incidental finding, during the abdominal surgical procedures performed for other abdominal pathology. ${ }^{6-10}$ Treatment options for Meckel's diverticulum are (1) Meckel's diverticulectomy, (2) resection of Meckel's diverticulum along with an adjacent small segment of ileum and ileoileal anastomosis, and (3) resection of Meckel's diverticulum along with an adjacent segment of ileum, cecum, part of the colon, and ileocolic anastomosis. ${ }^{6,9,11,12}$ For Meckel's diverticulum, surgical procedures can be accomplished, either by open surgery or laparoscopic techniques. ${ }^{6,9,11,12}$ Prophylactic resection of an incidentally detected Meckel's diverticulum remains a controversial subject. ${ }^{9,13}$ The present manuscript is a study of 84 children who were operated upon for Meckel's diverticulum, with a brief literature review.

\section{Materials and Methods}

It is a single-institution, retrospective, and descriptive study. It included infants, and children below 12 years, who were operated upon for Meckel's diverticulum during the study period. Hospital record considered in analysis was from January 1, 2000, to December 31, 2020 (21 years). It was performed at the author's department of pediatric surgery. Case records of children-who were operated upon for Meckel's diverticulum-were reviewed for their age, sex, clinical presentation, operative procedures performed, postoperative complications, and the outcome. Incidentally detected Meckel's diverticulum, which did not require surgical resection, was excluded from the present study. Institutional ethics committee clearance was obtained for waiver of the consent. It was exempted from review because of the retrospective nature of the study.

\section{Results}

For Meckel's diverticulum, a total of 84 children were operated upon during the study period. The male to female ratio was 3:1 for the present study. The demographics, clinical characteristics, operative findings, and postoperative complications for the children operated upon for Meckel's diverticulum are provided in - Table $\mathbf{1}$. The age and sex distribution of infants and children included in this study are provided in - Fig. $\mathbf{1}$. Clinical presentations of Meckel's diverticulum in infants and children are provided in - Fig. $\mathbf{2}$. The incidentally detected Meckel's diverticulum of $n=4$ children which also required surgical resection, and they were also included in the present study. Operative findings in infants and children with Meckel's diverticulum are detailed in -Fig. 3. The causes for the intestinal obstruction were congenital fibrous bands, attached from the tip of Meckel's diverticulum to the umbilicus ( - Fig. 4A), secondary intussusception ( - Fig. 4B), and adhesions. Gangrenous bowels were also evident in $41.66 \%(n=35)$ of the cases ( - Fig. 5A). Perforation of Meckel's diverticulum was documented in 17 children ( - Fig. 5B). The surgical procedures executed for Meckel's diverticulum in infants and children are detailed in - Fig. $\mathbf{6}$. The surgically resected Meckel's diverticulum/bowel segments, including Meckel's diverticulum, were subjected to histopathological examination. None of the specimens subjected to histology reported an ectopic mucosa of Meckel's diverticulum. They reported that the specimens consisted of bowel mucosa consistent with the small bowel. Postoperative complications were also documented in $8(9.52 \%)$ children. Three children $(3.57 \%)$ of the present study died during the postoperative period.

\section{Discussion}

In 1598, Meckel's diverticulum was described first by Wilhelm Fabricius Hildanus. ${ }^{1}$

In 1809 , the embryological and pathological features of the diverticulum of the distal ileum were described by Johann Friedrich Meckel, the Younger. ${ }^{1,3,4}$ It is a true diverticulum of the small intestine and consists of all the layers of the ileum. When it is present, it is located in the antimesenteric portion of the ileum. ${ }^{1,3}$ Most commonly, Meckel's diverticulum is remembered by the classic rule of $2 \mathrm{~s}$, although this is not the rule; it occurs in $2 \%$ of the population, mostly occurring within 2 years of age, two times more common in males, located 2 feet proximal to the ileocecal valve, 2 inches long, $2 \mathrm{~cm}$ in diameter, and it may contain two types of heterotopic mucosa, other than the ileal mucosa. ${ }^{1,6}$

In the present study of Meckel's diverticula, the mean age was $59.33 \pm 44.33$ months (median, 15 months) and ranged from 1 month to 12 years. Half of the children were 6 to 12 years of age, one-fourth were infants, and $23 \%$ were children of 1 to 5 years of age. Symptomatic Meckel's diverticula not only occur more frequently in infants and young children but also occur in older children and adults. ${ }^{1,3,5-9}$ Studies also evidenced that the frequency of symptomatic Meckel's diverticulum decreases with the 
Table 1 Demographics, clinical characteristics, operative findings, and postoperative complications details for children operated upon for Meckel's diverticulum $(n=84)$

\begin{tabular}{|c|c|c|c|}
\hline Description & Details & Number of cases & Percentage \\
\hline \multirow[t]{2}{*}{ Sex distribution } & Male & 63 & 75 \\
\hline & Female & 21 & 25 \\
\hline \multirow[t]{2}{*}{ Type of cases } & Symptomatic cases & 80 & 95.23 \\
\hline & Asymptomatic cases (incidentally detected) & 4 & 4.76 \\
\hline \multirow[t]{3}{*}{ Clinical presentation } & Acute abdomen & 76 & 90.47 \\
\hline & Gastrointestinal bleeding & 4 & 4.76 \\
\hline & Incidentally detected & 4 & 4.76 \\
\hline \multirow[t]{4}{*}{ Preoperative diagnosis } & Intestinal obstruction & 42 & 50 \\
\hline & Intussusception & 17 & 20.23 \\
\hline & Perforation peritonitis & 17 & 20.23 \\
\hline & Gastrointestinal bleeding & 3 of 4 & 3.57 \\
\hline \multirow[t]{2}{*}{ Operative findings } & Bowel gangrene-No & 49 & 58.33 \\
\hline & Bowel gangrene-Yes & 35 & 41.66 \\
\hline Pathological lead point & Secondary intussusception & 17 & 20.23 \\
\hline \multirow[t]{2}{*}{ Bowel resection } & Yes, required & 52 & 61.9 \\
\hline & No, not required & 32 & 38.09 \\
\hline Postoperative complications & $\begin{array}{l}\text { Major complications: } \\
\text { (i) Anastomotic leak, } \\
\text { (ii) burst abdomen, } \\
\text { (ii) septicemia }\end{array}$ & $\begin{array}{l}8 \\
(3) \\
(3) \\
(2)\end{array}$ & $\begin{array}{l}9.52 \\
(3.57) \\
(3.57) \\
(2.38)\end{array}$ \\
\hline Mortality & Postoperative mortality & 3 & 3.57 \\
\hline
\end{tabular}

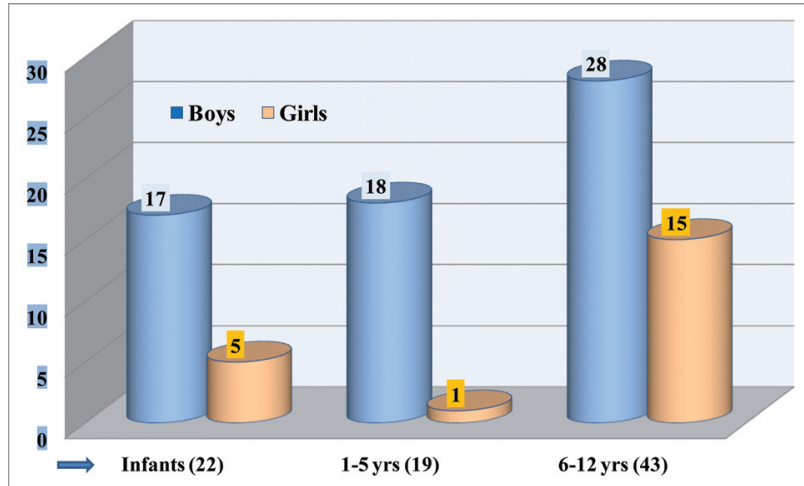

Fig. 1 Age and sex distribution of infants and children with Meckel's diverticulum.

advancing age. ${ }^{5,6,10}$ In general, symptomatic Meckel's diverticula are more common in males. The documented male to female ratio was $1.5: 1$ to $4: 1$. The above facts were also observed in many of the studies, published on Meckel's diverticulum, including the present study. ${ }^{1,5,6,9-12}$

Clinical presentation of symptomatic Meckel's diverticula varies from study to study. The clinical presentation also varies with the age of patients. ${ }^{1,3,6,8-10}$ Most of the Meckel's diverticula are asymptomatic. It may present with abdominal pain, diverticulitis, lower gastrointestinal bleeding, in-

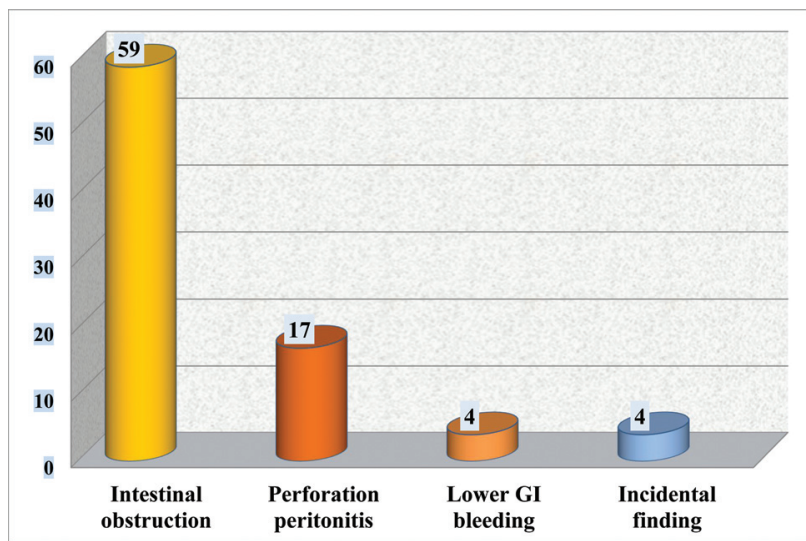

Fig. 2 Clinical presentation of Meckel's diverticulum in infants and children.

testinal obstruction, and perforation peritonitis. ${ }^{1,3,6,8-12}$ Seventy percent of Meckel's diverticula of the present report presented with the features of intestinal obstruction. Another one-fifth of the cases presented with the features of perforation peritonitis. Some studies also documented findings similar to the present study that the most common presentation was intestinal obstruction. ${ }^{6,10,11,14,15}$ Contrary to some of the studies of Meckel's diverticulum in children, in the present report, only 4 (4.76\%) children presented with recurrent lower gastrointestinal bleeding. ${ }^{9,16}$ 


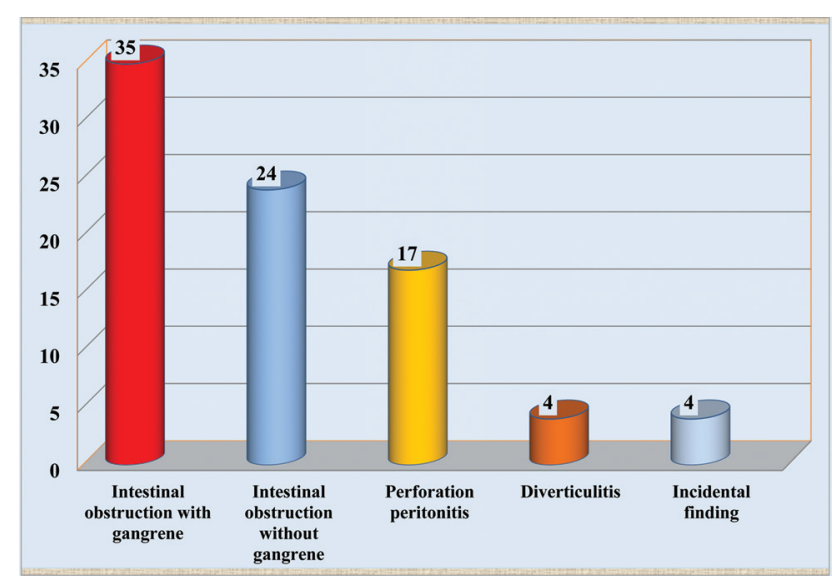

Fig. 3 Operative findings of Meckel's diverticulum in infants and children.

All the cases were investigated with plain skiagram and ultrasonography (USG) of the abdomen in the present report. Routine hematological and biochemical investigations were also obtained. During the preoperative sonographic abdominal examination, dilated bowel loops were detected in children presented with intestinal obstruction. Peritoneal fluid collection and free gas in the abdomen were documented in children presented with perforation peritonitis. In 17 children, intussusception was diagnosed as a cause for intestinal obstruction. During USG evaluation of the children of the present report, none reported Meckel's diverticulum as a cause for intestinal obstruction or intussusception. Four children of the present series presented with recurrent lower gastrointestinal bleeding. All four children were investigated with Meckel's scan, and three of the scans were positive for the ectopic gastric mucosa.

Diagnosis of Meckel's diverticulum in the preoperative period is challenging, especially for the cases presenting with intestinal obstruction and perforation peritonitis, and in such cases, it was detected during the operative procedures. ${ }^{6}$ In the present study also the Meckel's diverticula were detected during the operative procedures done for intestinal obstruction/perforation peritonitis. In children, it is possible to diagnose intussusception in as many as $100 \%$ of the cases on USG evaluation, but Meckel's diverticulum as a cause for
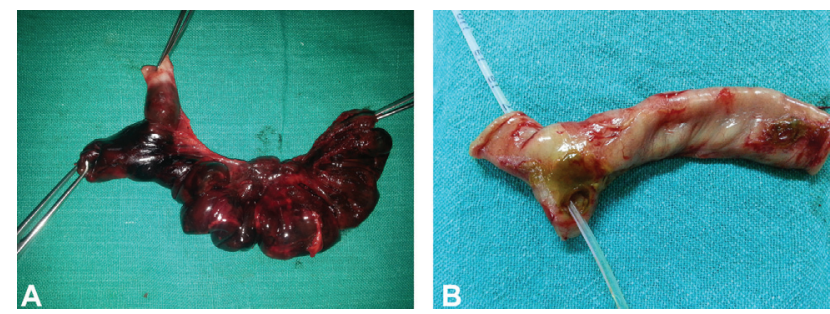

Fig. 5 (A) Resected specimen showing gangrenous ileum and Meckel's diverticulum. (B) Resected specimen showing ileal segment and perforated Meckel's diverticulum.

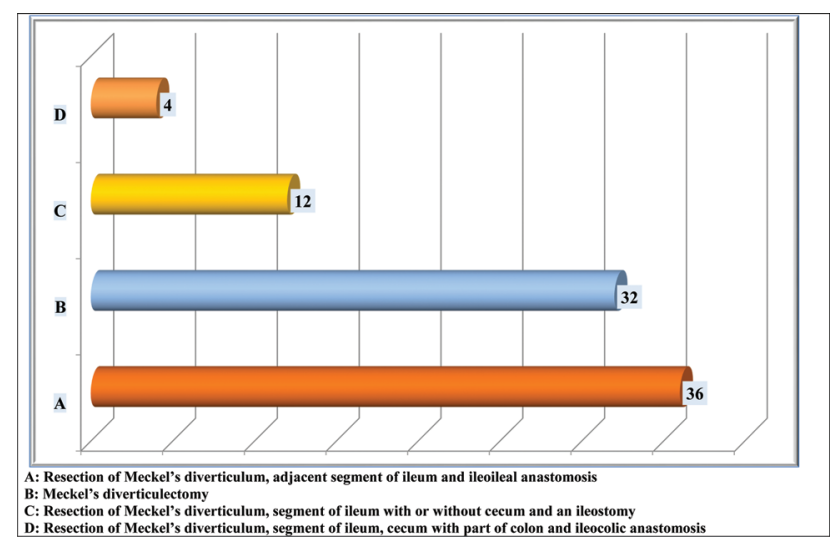

Fig. 6 Operative procedures performed for Meckel's diverticulum in infants and children.

intussusception is rare. If detected, it may be seen as a tubular/cystic structure attached to the ileal loop. ${ }^{17}$ On computed tomography scan, Meckel's diverticulum usually appears as a blind-ending tubular/cystic structure, attached to the ileal loop, and maybe with typical "gut signature sign," but the detection rate of symptomatic and asymptomatic Meckel's diverticula varies. ${ }^{17,18}$ Meckel's scan has a very high diagnostic value for the detection of the ectopic gastric mucosa. The sensitivity and specificity of Meckel's scan for detection of ectopic gastric mucosa vary from study to study. ${ }^{9,12,14,17,19,20}$

The standard treatment of Meckel's diverticulum is surgical resection. Surgical resection is done either with or
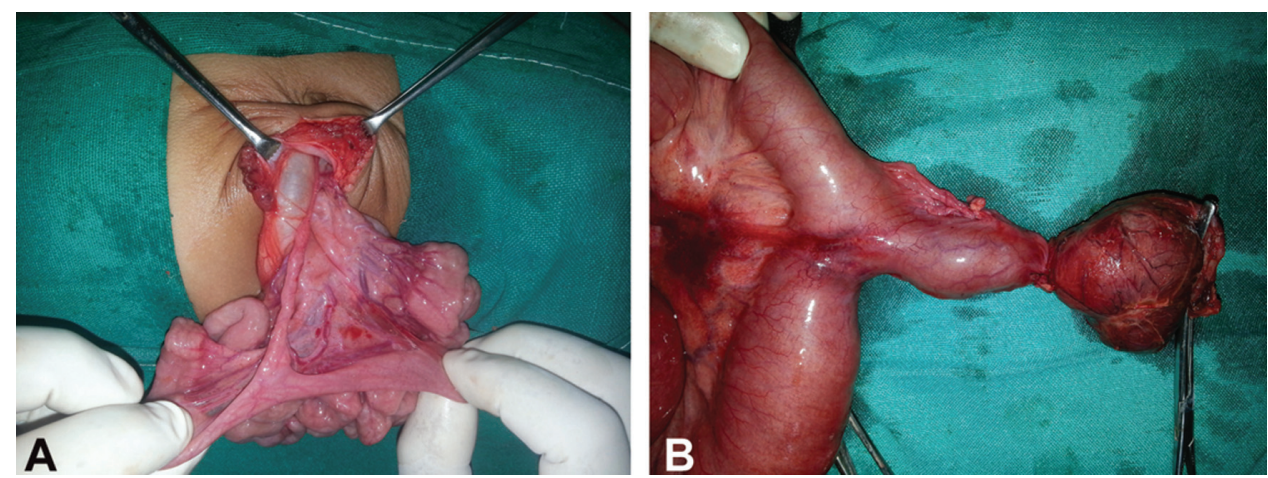

Fig. 4 (A) Operative photograph showing Meckel's diverticulum with fibrous band. (B) Operative photograph showing Meckel's diverticulum with cystic dilatation. 
without resection of an adjacent segment of the ileum and

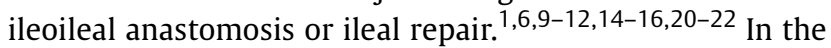
present study, in 36 (42.85\%) children, resection of Meckel's diverticulum with an adjacent segment of ileum and ileoileal anastomosis was performed. Resection of Meckel's diverticulum without resection of an adjacent segment of ileum with the ileal repair was done in 32 (38.09\%) children. Thirty-five (41.66\%) children revealed gangrene of the bowel, and it was detected during the surgical procedures. Resection of the bowel segment was required in 52 (62\%) children, and in two-third, the requirement was due to the presence of gangrene of the bowel. Some of the factors responsible for the bowel gangrene and requirement of bowel resection during the surgical therapy were (1) reluctant for medical care for the early symptoms of acute abdomen by the parents, (2) delay in the diagnosis, (3) delayed referral to the pediatric surgical center, (4) delay in seeking surgical therapy, and (4) reluctant for surgical therapy/delay in consent for the surgical therapy.

Management of Meckel's diverticulum detected during the surgical procedures done for other abdominal pathology is a controversial subject. Prophylactic resection of silent Meckel's diverticulum is also a controversial subject. ${ }^{13,14,16,20,23,24}$ Soltero and Bill and Zani et al in their study/review concluded that prophylactic removal of incidentally detected Meckel's diverticulum is not justifiable. $^{23,24}$ Specific criteria are suggested for the prophylactic resection of an incidentally detected Meckel's diverticulum. Most importantly, the operating surgeon(s) must justify either to remove or not to remove, Meckel's diverticulum detected incidentally, for the best interest of their cases. ${ }^{13}$

In four children of the present study, Meckel's diverticulum was detected incidentally, and that required surgical resections. Meckel's diverticulectomy was also performed during an appendectomy in an 11-year-old girl for a thickened base of Meckel's diverticulum. In a 9-year-old boy, Meckel's diverticulectomy was also performed along with the surgical procedure done for an obstructed umbilical hernia. In a 12-year-old girl, an exploratory laparotomy was performed for perforation peritonitis. She had two ileal perforations, and one more perforation was documented at the base of Meckel's diverticulum. Her Meckel's diverticulum was resected, along with a small segment of the ileum. Continuity of the ileum was restored with ileoileal anastomosis. Her ileal perforations required repair. A male neonate was operated upon for scrotal fecal fistula and intestinal obstruction due to obstructed inguinal hernia. Meckel's diverticulum was also evident adjacent to an ileal perforation. Meckel's diverticulum was also resected, along with the perforated ileum, and ileal continuity was restored by ileoileal anastomosis.

Postoperative complications were documented in eight (9.5\%) children of the present study. The complications documented were anastomotic leak $(n=3)$, burst abdomen $(n=3)$, and septicemia $(n=2)$. These cases, complicated with the anastomotic leak and burst abdomen, required additional surgical procedures for the management of their complications. Three children, complicated with an anastomotic leak, required reexploration for the management of their complications. Additional surgical procedures were also required for three children who had burst abdomen. Two children complicated with septicemia were managed conservatively. During the immediate and late postoperative periods, following the resection of Meckel's diverticulum, various complications were also reported by various authors that are as follows: the infection of the wound, intraabdominal abscess, anastomotic leakage, peritonitis, burst abdomen, and adhesion leading to intestinal obstruction. $6,7,9,11,14,20,25$

Some authors also documented mortality following the surgical resections executed for Meckel's diverticulum. ${ }^{11,20,25}$ In the present study, three (3.57\%) children died during the postoperative period. The age of the children, all boys, who died during the postoperative period, was 6 years, 18 months, and one month. Anastomotic leak $(n=1)$, septicemia $(n=1)$, and preexisting poor general condition with septicemia $(n=1)$ were the causes of death.

To conclude, Meckel's diverticulum was one of the common causes of acute intestinal obstruction in infants and children. Three-fourths of Meckel's diverticulum was documented in males. Clinically, $70 \%$ of children presented with the features of acute intestinal obstruction. In one-fifth of children, it was responsible for secondary intussusception. In $40 \%$ of children, gangrenous bowel was documented during the surgical procedures. In $60 \%$ of children, resection of a bowel segment was required during the surgical procedures. In infants and children, early diagnosis, timely referral to the pediatric surgical center, and institution of the appropriate/surgical therapy for acute abdomen/intestinal obstruction may significantly prevent/reduce the development of bowel gangrene and the requirement of bowel resections.

Note

This study was presented at the Pediatric Surgeons Club, Bhopal on September 21, 2019.

Conflict of Interest

None declared.

\section{References}

1 Snyder CL. Meckel Diverticulum. In: Coran AG, Adzick NS, Krummel TM, et al., eds. Pediatric Surgery 7th edition. Philadelphia, PA: Elsevier-Saunders; 2012:1085-1092

2 Mullassery D, Losty PD. Omphalomesenteric duct remnants. In: Puri P, Höllwarth M, eds. Pediatric Surgery: Diagnosis and Management. Berlin, Germany: Springer; 2009:491-496

3 Campbell BT. Meckel's diverticulum and other omphalomesenteric duct remnants. In: Wyllie R, Hyams JS, eds. Pediatric Gastrointestinal and Liver Disease. 4th edition. Philadelphia, PA: Elsevier-Saunders; 2011:572-575

4 Gluecklich B. Johann Friedrich Meckel, the Younger (1781-1833). Am J Surg 1976;132(03):384-386

5 Alemayehu H, Hall M, Desai AA, St Peter SD, Snyder CL. Demographic disparities of children presenting with symptomatic Meckel's diverticulum in children's hospitals. Pediatr Surg Int 2014;30(06):649-653 
6 Hansen CC, Søreide K. Systematic review of epidemiology, presentation, and management of Meckel's diverticulum in the 21st century. Medicine (Baltimore) 2018;97(35):e12154

7 Groebli Y, Bertin D, Morel P. Meckel's diverticulum in adults: retrospective analysis of 119 cases and historical review. Eur J Surg 2001;167(07):518-524

8 Sagar J, Kumar V, Shah DK. Meckel's diverticulum: a systematic review. J R Soc Med 2006;99(10):501-505

9 Lin XK, Huang XZ, Bao XZ, Zheng N, Xia QZ, Chen CD. Clinical characteristics of Meckel diverticulum in children: a retrospective review of a 15-year single-center experience. Medicine (Baltimore) 2017;96(32):e7760

10 Park JJ, Wolff BG, Tollefson MK, Walsh EE, Larson DR. Meckel diverticulum: the Mayo Clinic experience with 1476 patients (1950-2002). Ann Surg 2005;241(03):529-533

11 Rattan KN, Singh J, Dalal P, Rattan A. Meckel's diverticulum in children: Our 12-year experience. Afr J Paediatr Surg 2016;13 (04):170-174

12 Huang CC, Lai MW, Hwang FM, et al. Diverse presentations in pediatric Meckel's diverticulum: a review of 100 cases. Pediatr Neonatol 2014;55(05):369-375

13 Żyluk A. Management of incidentally discovered unaffected Meckel's diverticulum - a review. Pol Przegl Chir 2019;91(06): 41-46

14 St-Vil D, Brandt ML, Panic S, Bensoussan AL, Blanchard H. Meckel's diverticulum in children: a 20-year review. J Pediatr Surg 1991;26 (11):1289-1292

15 Ruscher KA, Fisher JN, Hughes CD, et al. National trends in the surgical management of Meckel's diverticulum. J Pediatr Surg 2011;46(05):893-896
16 Menezes M, Tareen F, Saeed A, Khan N, Puri P. Symptomatic Meckel's diverticulum in children: a 16-year review. Pediatr Surg Int 2008;24(05):575-577

17 Kotha VK, Khandelwal A, Saboo SS, et al. Radiologist's perspective for the Meckel's diverticulum and its complications. Br J Radiol 2014;87(1037):20130743

18 Kawamoto S, Raman SP, Blackford A, Hruban RH, Fishman EK. CT detection of symptomatic and asymptomatic Meckel diverticulum. AJR Am J Roentgenol 2015;205(02):281-291

19 Sinha CK, Pallewatte A, Easty M, et al. Meckel's scan in children: a review of 183 cases referred to two paediatric surgery specialist centres over 18 years. Pediatr Surg Int 2013;29(05):511-517

20 Chen Q, Gao Z, Zhang L, et al. Multifaceted behavior of Meckel's diverticulum in children. J Pediatr Surg 2018;53(04):676-681

21 Duan X, Ye G, Bian H, et al. Laparoscopic vs. laparoscopically assisted management of Meckel's diverticulum in children. Int J Clin Exp Med 2015;8(01):94-100

22 Ezekian B, Leraas HJ, Englum BR, et al. Outcomes of laparoscopic resection of Meckel's diverticulum are equivalent to open laparotomy. J Pediatr Surg 2019;54(03):507-510

23 Soltero MJ, Bill AH. The natural history of Meckel's diverticulum and its relation to incidental removal. A study of 202 cases of diseased Meckel's diverticulum found in King county, Washington, over a fifteen year period. Am J Surg 1976;132(02):168-173

24 Zani A, Eaton S, Rees CM, Pierro A. Incidentally detected Meckel diverticulum: to resect or not to resect? Ann Surg 2008;247(02): 276-281

25 Robinson JR, Correa H, Brinkman AS, Lovvorn HN III. Optimizing surgical resection of the bleeding Meckel diverticulum in children. J Pediatr Surg 2017;52(10):1610-1615 